So far we have only discussed the clinical aspect of the question. In the works of the various authorities, which I have consulted, I can find no mention of the presence of calcium in the scleral tissues, but its presence has been demonstrated for me by an analyst with the micro-spectroscope.

I think that I have made out a fairly strong case for supposing that progressive myopia is in reality a symptom of calcium deficiency. I have heard that the administration of Bemax has been of use in arresting progressive myopia. I have not had sufficient experience of its use as yet to speak of it as a substitute for calcium and parathyroid, but on observing its analysis table one sees that calcium is present in a fairly high proportion. Bemax contains vitamins, and they may assist in the introduction of the calcium into the tissues. Thus, if Bemax is really efficacious in arresting progressive myopia, its action may well be due to its calcium content.

I hope that this paper'may induce other oculists to try the administration of calcium in cases of myopia under their care, so that they may see if they obtain results similar to mine.

In the Brit. Jl. of Ophthal., Vol. XI, No. 5 (May, 1927) Mr. D. J. Wood of Cape Town in his paper states that for some years he "had been aware that some ocular conditions are associated with or caused by a deficiency in the amount of calcium in the blood." He then describes several cases in young children suffering from myopia. He points out that progression goes hand in hand with calcium deficiency. This observation of his has certainly been borne out by my own. He also points out the necessity of prescribing parathyroid extract with the calcium.

\title{
OXFORD OPHTHALMOLOGICAL CONGRESS XXIInd ANNUAL MEETING, I932
}

THE meeting of the Congress took place on July 7, 8 and 9 at Keble College, Oxford and the papers were read in the Department of Human Anatomy and in the University Museum.

The retiring Master, Mr. BERnard CRIDLAND, extended a welcome to all those present and in particular to those who had travelled a long way to attend the Congress, among whom were Dr. Luther Peter of Philadelphia, Professor van der Hoeve (Leiden), and Professor Pascheff of Sofia. Mr. Cridland paid a special tribute to the Secretary, Mr. Russ Wood, whose work and efforts were invaluable to the success of the Congress.

$\mathrm{He}$ welcomed Mr. Cyril Walker as the New Master and performed the ceremony of installation. 
Address by Dr. Luther Peter of Philadelphia :- "The Treatment of Non-paralytic Strabismus, excluding operative details."

Dr. Luther Peter gave an outline of the modern conception of concomitant squint and urged the necessity of treatment as soon as the diagnosis was made. He described the types of squint, convergent and divergent, unilateral and alternating, and stated that the prevailing type was the unilateral esotropia. Aetiological factors consisted of a defective fusion faculty; a refractive error, usually hypermetropia with a higher degree in one eye than the other: hereditary and other precipitating causes. The barriers to establishing an effective cure are total amblyopia and defects in the central field of vision. It is essential to treat concomitant squint before the sixth year of life. The refractive error should receive full correction at the earliest moment. Children of 12 or 16 months of age will use glasses. The refractive error should be "checked up" once a year. Whilst wearing glasses the squint may. become alternating in type, and glasses may fail to give a satisfactory result because of excessive deviation and anatomical changes in the internal rectus. Amblyopia does not occur in true alternating squint and when present is often associated with a small relative scotoma. It rarely develops after the age of 7 years. If no attempt is made to correct it, it increases. Occlusion may in the course of six to eight weeks bring about a transference of the squint and also lowered visual acuity from one eye to the other. Atropine in the fixing eye has the disadvantage that the child is sometimes unable to tolerate the glare of light and so cannot have its full share of sunshine. A soft black mesh occlusion bandage is more effective. When amblyopia is present occlusion should be practised for longer periods than in other cases-three to six hours. Dr. Luther Peter spoke of the importance of affording the child useful and interesting occupation at the near point and of gaining the co-operation and enthusiasm of the parents.

Operative treatment is indicated in those cases of squint which are 25 degrees or more and because of this mechanical defect fail to respond to orthoptic training. Dr. Luther Peter prefers to operate about the 3 rd or 4 th year of life and does so under general anaesthesia. He employs advancement of the external rectus muscle, resection of part of this muscle and recession of the internal rectus according to the degree and nature of the squint. In many cases single binocular yision takes place within one month after operation. In cases where there are 35 degrees or more of squint two operations may be necessary. Orthoptic training is carried on after operation. Recession is recommended as a reserve or supplementary operation and the muscle should not be recessed more than five millimetres behind its original insertion. It is especially valuable when there is contractive of the internal rectus. 
Dr. Luther Peter gave an outline of stereoscopic training; training by prisms base out and then base in ; and the indications for the various types of surgical procedure.

This paper was keenly discussed. Mr. Bernard Chavasse (Liverpool) stated that treatment of squint was unsatisfatory in the bulk, the sequelae of correction producing a vicious circle. He believes that the problem of squint concerns (i) Phylogeny and the study of the way in which the visual axes change and the stages through which primitive conjugation passes. (ii) Neurology, the primitive labyrinthine control, the reflex of primatral convergence and the bifoveal reflex of ocular posture. (iii) Psychological factors, the operation of the steroscopic instinct, the frustration of which leads to a state of atavism and (iv) Aetological factors. $\mathrm{He}$ mentioned the peculiarities of squint associated with serious ocular lesions. Mr. Chavasse urged that preventive work might be done by examining the refraction of children where one or other parent has possessed a squint.

$\mathrm{Mr}$. A. ORMOND (London) spoke of hereditary factors in the production of squint and gave the pedigrees of some families suffering from hypermetropia. He believes that squint is a manifestation of an interference with the normal development of the eye after birth.

Mr. E. Alabaster (Birmingham) described the work done by the personel of his orthoptic clinic. He finds that occlusion improves the visual acuity and the tone of the extra-ocular muscles. Improvement in the acquirement of accurate projection followed a method of treatment known as "flashing" on to the macula. Mr. Alabaster showed a series of interesting charts comparing the results obtained in visual acuity, the angle of squint and the fusion faculty by occlusion, the synoptophore and cheiroscope and after operation.

$\mathrm{Mr}$. Williamson-Noble (London) described familiar factors in the aetiology of squint and pointed out the prophylactic work that might be done in this connection. He recalled a case where a haemorrhage into the right optic nerve sheath at birth had produced a squint associated with a visual field defect. As an alternative to occlusion he uses atropine in the fixing eye and places before this a plane glass, the squinting eye having the full correction. He emphasized the importance of using a cylinder during retinoscopy and of the duochrome test in determining the spherical correction.

He emphasized the importance of using a cylinder during retinoscopy and of the duochrome test in determining the spherical correction.

Dr. STEwart Barrie (Glasgow) gave an analysis of 71 cases which had been under his care and expressed his deductions from the results of these. 
Mr. Malcolm Hepburn stressed the importance of anatomical correction of the visual axes. He believes that tenotomy is a useful operation and that the results are only unsatisfactory where the surgeon has erred in his judgment. Advancement he reserves for bad cases and then uses it combined with tenotomy.

Mr. Stenhouse Stewart (Hull) said that squint is concerned with the problem of innervation and that the fault lies chiefly with the binocular innervation of the internal recti. Peripheral irritation may give rise to over-action of both internal recti. Mr. Stewart advocates the use of a ruby glass before the fixing eye in place of occlusion.

Mr. MADDox (Bournemouth) paid a tribute to Dr. Luther Peter's paper and emphasized the importance of giving the child interesting occupation during a period of occlusion. The two bugbears in treatment are cerebral and retinal amblyopia and false projection.

Professor VAN DER HoEve (Leiden) said that much depended upon the individuality of the squinter and the oculist. The treatment of squint is a difficult field. He believes that it is not right to give glasses for such small degress of hypermetropia as $0.5 \mathrm{D}$. and $1.0 \mathrm{D}$.

Dr. Arthur Hall (Professor of Medicine in the University of Sheffield) gave an address on "The Oculogyric attacks of Chronic Epidemic Encephalitis," accompanied by cinematograph illustrations.

These attacks have certain features in common, they recur, the attacks are of varying duration, they are uninfluenced by treatment, and vision is normal between the attacks. Charts were shown to illustrate these points as regards the duration of the attack, the state of the lids, and deviation of the eyes when the gaze was fixed, when there was inability to open the eyes and during oculogyric attacks. When the attack sets in the eyes shoot in an upward direction. The onset is sudden but sometimes gradual and both sexes are affected about equally. Young persons are more commonly affected but the disease may occur at any age. In the early stages the eyes can be pulled down during an attack but go up again. An attack may be induced by watching a football match or the cinematograph and can in some instances be cut short by suggestion, the termination is in sleep and the attack is finished on waking up. All cases exhibit the Parkinsonian features. The aetiology remains uncertain. Dr. Hall gave an analysis and showed cinematograph pictures to compare the movements of the eyeball during sleep, in winking, and on attempting to close the eyelids in cases of Bell's palsy. He demonstrated diagrams of his conception of the nervous mechanism involved when the eyes are closed and opened.

In the discussion that followed Dr. Gibson (Oxford) commented on Dr. Hall's address as being an excellent exposition of clinical medicine at its best. 
Professor Pascheff (Sofia) and Mr. Montague Harston also took part in the discussion.

Mr. Lindsay REa (London) demonstrated a new cataract knife made with a longer and thinner blade $(31 \times 1.5 \mathrm{~mm}$.) than other knives.

Mr. Zorab (Southampton) read a paper on "Glaucoma Simplex Familialis" and illustrated this by pedigrees.

Mr. Neame took part in the discussion and described a case that had come under his care.

Mr. H. B. Stallard demonstrated the microphotographs of "Two unusual cases of Sarcoma of the Choroid," one occurring in an eye affected with chronic uveits and the other in a woman, aged 27 years, who was six months pregnant.

\section{The Doyne Memorial Lecture.}

Professor van DeR Hoeve (Leiden) gave the Doyne Memorial Lecture and chose as his subject "The Ocular Signs in the Phakomatoses of Bourneville, von Hippel-Lindau and of Recklinghausen."

He spoke of the honour he felt in being invited to deliver this lecture and before he began he paid a tribute to the memory of the late Robert Walker Doyne, the founder of the Congress.

Professor van der Hoeve presented a chart comparing the pathological lesions met with in the organs of the human body in the phakomatoses as described by Bourneville, van Hippel and Lindau and Recklinghausen. He believes that this group of anomalies are one and the same disease, and that the name phakomatosis embraces them all. An hereditary factor is present. In the brain, spinal cord and canda equina there are glial and ganglionic cells, and these possess embryonic characters and are not differentiated. Cysts may be present particularly in the cerebellum and some parts of these tumours are angiomatoses. Glial proliferation may be primary or secondary. Similar pathological changes may occur in other nerves such as the ciliary nerves and nerves of the cornea. Photographs of sebaceous adenomata, multiple pro-adenomata, horse-shoe kidney, and phakomatoses of the optic nerve, the papilla and retina were shown. The lecture was admirably illustrated by fundus paintings, radiograms, histological sections and photographs of organs removed postmortem. Professor van der Hoeve has made a most thorough and painstaking survey of this subject, which is of interest to the general physician, the surgeon, neurologist, dermatologist, ophthalmologist, gyneaecologist and radiologist.

The master presented the Doyne Memorial Medal and expressed thanks to Professor van der Hoeve. 
Mr. Burdon Cooper (Bath) read a paper on "Some Observations in the Practice of Refraction." $\mathrm{He}$ advocates the use of crossed cylinders in determining the strength and axis in the final correction. Mr. Burdon Cooper emphasized the importance of first finding the proper spherical correction and after every change of the sphere re-testing the cylinder for its amount and axis. Necessary changes in the axis varied from 5 to 45 degrees, the average being 5 to 15 degrees. It is probable that the refraction becomes altered by lental changes produced during an effort at accommodation. Mr. Burdon Cooper uses the orthogon in determining the axis and amount of astigmatism. It is better to undercorrect astigmatism with the rule and to over-correct astigmatism against the rule.

This paper was keenly discussed by Messrs. Harrison Butler, Young, Williamson-Noble, Preston, Dastoor, Alabaster, Stewart Barrie, Hanson, Lindsay Rea, Alston Hughes, Whittington and Dr. Luther Peter.

Dr. Ronald Canti (London) gave an "Address and Cinematograph Demonstration of Living Tissue Cultivated in Vitro."

This work was carried out in the Strangeways Laboratory at Cambridge and also at St. Bartholomew's Hospital. The cells for living tissue culture were taken from the embryo chick, the rat, rabbit, and Yensen's rat sarcoma. The cinematograph was speeded up so that in three-quarters of an hour there was shown three weeks actual experimental work. The effects of cell reproduction, phagocytosis, growth and the results of irradiation of sarcoma by the beta rays of radium were amazing. Similar work with dark ground illumination was also shown.

Professor PASCHEFF (Sofia) read a paper "On the Laws of True Trachoma." He described the follicular reaction of the conjunctiva to many reagents. The follicles may be diffuse, small, confluent, and may burst and cicatrise. Trachoma follicles have a germinating centre and are confluent. The pathological changes at the limbus in trachoma show areas of thickening and germinating follicles divided by vessels which take origin from the upper fornix and phica semilunaris.

Colonel R. E. Wright (Madras) in discussing this paper spoke of the difficulties in making a diagnosis. Mr. Montague Harston and $\mathrm{Mr}$. Harrison Butler also made contributions.

Mr. GEORGE BLACK described the "Treatment of Detached Retina by Multiple Trephining and the Application of Caustic to the Choroid." The retinal hole or tear is accurately located and the operation planned to promote a chemical choroiditis in its immediate vicinity, omnopon grs. $1 / 3$ and scopolamine grs. $1 / 100$ are given before operations. Cocaine 4 per cent. is used for local anaesthesia. A large incision in the conjunctiva and Tenon's 
capsule is made and care taken to obtain complete haemostasis. Trephines $1.5 \mathrm{~mm}$. in diameter are used. Pieces of sclera are removed piecemeal until the choroid is reached. The exposed choroid is touched with solid cocaine before applying the caustic. Absolute haemostasis is essential. The stick of caustic soda is mounted in wax and the end sharpened to form a point just before operation. The choroid is touched for one second in each trephine hole and then swabbed with dilute acetic acid one per cent. The choroid is then perforated by a blunt instrument, one third of the number of trephine holes being punctured. Mr. Black described the post-operative treatment and gave an analysis of $3 \tau$ cases. The chief complications are vitreous haemorrhage, massive uveitis with increase of the detachment and thrombosis of a vena vorticosa.

Mr. H. D. Dastoor (Bombay) followed with a paper on "Recent Advances in the Operative 'Treatment of Detachment of the Retina."

Other papers of interest were "Some Suggestions regarding the Treatment of Amblyopia ex anopsia" by Mr. KAY ShARp (Leeds) and "The Aetiology of Miner's Nystagmus by Mr. W. S. Rochr: (Newport). In this latter paper investigations were carried out on the quality of the coal being worked, the age of the pits in years, the limits of volatile matter in coals, the percentage of electric lamps in use, depth and thickness of seam, method of working, barometer readings, humidity at the face, velocity of air at the face in feet per minute, analyses of air, carbon dioxide, methane, oxygen, carbon monoxide, the percentage of light reflected from the coal, the temperature at the face and general conditions.

\section{Demonstrations in the Scientific and Commercial Museums.}

Miss Maddox (London). A test series of synoptophore slides for the purpose of grading the intensities of binocular vision.

A stereoscope on a kinetic principle.

Professor Pascheff (Sofia). Histological slides demonstrating dystrophia hereditaria corneae and conjunctivitis pustulosa suppurativa.

Mr. Arthur Greene (Norwich). A tiny toy projectileless pistol which caused a traumatic cataract in a child.

Mr. S. Tudor Thomas (Cardiff). Transplantation of scleral tissue on to the cornea of a rabbit.

Colonel R. E. Wright (Madras). A series of water colour pictures of external diseases of the eye taken in the Madras Ophthalmic Clinic, and a cinematograph demonstration of the ophthalmic clinic in Madras.

Mr. Kay Sharp (Leeds). Demonstration of the optophore.

Demonstrations of optical apparatus were given at the stalls of the following firms :- Messrs. Clement Clark, Clifford Brown, 
Dixey, Hamblin, and Keeler. Messrs Down Bros. and Weiss exhibited surgical instruments and Messrs. Pulman's a stall for stationery, files and card index cabinets.

\section{Social Events.}

The Annual Dinner of the Congress was held in the Hall of Keble College on Thursday, July 7.

On the same day the members of the Congress were received by Professor and Mrs. Townsend at tea in New College.

The success of this Congress is characterized by the high scientific standard of many of the papers and the corporate life in Keble College which fosters a spirit of bonhomie and promotes informal and valuable discussions on medical and other matters.

H. B. Stallard.

\section{COUNCIL OF BRITISH OPHTHALMOLOGISTS}

\section{Report on the Subject of Compensation for Eye Injuries}

THE Council of British Ophthalmologists having considered the subject of Compensation for Eye Injuries has arrived at the following conclusions :-

The attention of the Council was drawn to this matter by a paper read by Dr. J. Paterson of Edinburgh to the Ophthalmological Society of the United Kingdom in 1931, from which the following is a quotation :-

"The greatest advance in ophthalmic compensation would be a definite scale of payment, on a percentage basis, for the actual blinding or loss of an eye. If such payment were made immediately, and without question, where the loss of an eye was proved, much of the tendency to remain off work would, in my opinion, be counteracted. The present methods are calculated to arouse a valetudinarian habit of mind in the workman, and the period of incapacity tends to be greatly prolonged."

It is admitted that in many, if not in most, occupations, the employee could learn to perform his work and earn the normal wages, with a single eye, and if we were dealing with an acconlmodating employer, a willing employee, and a guarantee of continued employment, the present form of compensation, i.e., 